
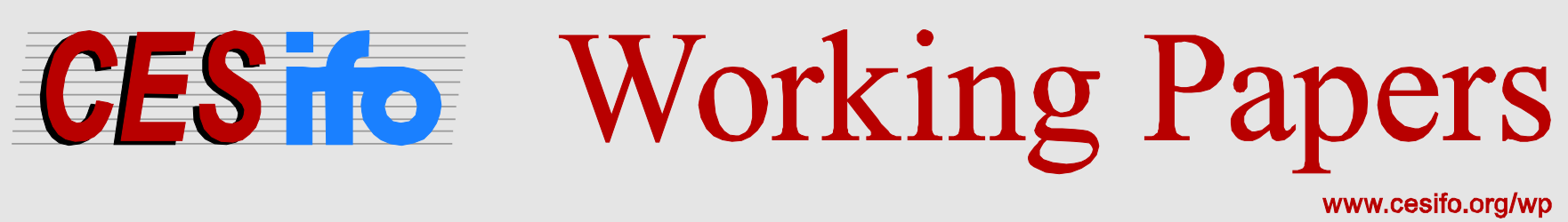

\title{
A Neglected Semi-Stylized Fact of Daily Stock Returns
}

\author{
Walter Krämer
}

\author{
CESIFO WORKING PAPER NO. 5806 \\ CATEGORY 7: MONETARY POLICY AND INTERNATIONAL FINANCE \\ MARCH 2016
}

An electronic version of the paper may be downloaded

- from the SSRN website:

- from the RePEc website:

www.SSRN.com

Www.RePEc.org

- from the CESifo website:

www.CESifo-group.org/wp 


\title{
A Neglected Semi-Stylized Fact of Daily Stock Returns
}

\begin{abstract}
We plot aggregated daily stock returns with absolute value less than $\mathrm{x}$ against $\mathrm{x}$ and show empirically that this often produces a typical spoon-shaped pattern which indicates a special type of asymmetry which has not been widely discussed before. This pattern disappears when individual returns are averaged; it is also absent in stock price indices, which points to explanations based on firm-specific drivers of returns.
\end{abstract}

JEL-Codes: C400, G120, G140.

Keywords: stock returns, skewness, symmetry.

\author{
Walter Krämer \\ Faculty of Statistics \\ TU Dortmund \\ Dortmund / Germany \\ walterk@statistik.tu-dortmund.de
}

Research supported by DFG-Sonderforschungsbereich 823. I am grateful to Simon Neumärker and Kaya Miah for expert computational assistance and to Joachim Grammig, André Güttler and Günter Bamberg for helpful discussions and comments. 


\section{Introduction and Summary}

Let $r_{t}$ be some (time-continuous) daily stock return (adjusted for dividends, stock-splits and so on). This paper is concerned with distributional (as opposed to time-series) properties of $r_{t}$. Typical among these are heavy tails as evidenced by a curtosis larger than 3, i.e. larger than for normality, or the near independence of $\left|r_{t}\right|$ and $\operatorname{sign}\left(r_{t}\right)$ (with equal probabilities for positive and negative), see e.g. Granger and Ding (1995), Granger et al. (2000), Rydén et al. (1998), Cont (2001) or Teräsvirta and Zhao (2011), among many others.

Below we are concerned with the relationship between $\left|r_{t}\right|$ and $\operatorname{sign}\left(r_{t}\right)$. That these cannot be exactly independent, at least under the standard assumption that the return density is univariate and symmetric, follows at once from the fact that $\sum_{1}^{T} r_{t}>0$ for large $T$ and almost all stocks (otherwise, there would be no incentive to hold them). In technical terms,

$$
E\left(r_{t}\right)=\mu>0
$$

where, for daily data, $\mu_{t}$ is small and often neglected, but still positive. This then implies that, under standard assumptions, returns with absolute values less than $\mu$ are more likely to be positive than negative.

The present paper argues that, even after taking (1) into account and considering $\left|r_{t}-\mu\right|$ instead, independence of $\left|r_{t}-\mu\right|$ and $\operatorname{sign}\left(r_{t}-\mu\right)$ does not obtain in practice; in fact, it is violated in a very peculiar fashion. Sticking to the assumption that the unconditional density of $r_{t}$ is time invariant, unimodal and symmetric, it is immediately obvious from the form of the density function that

$$
0<E\left(r_{t}|| r_{t} \mid<x\right)<\mu
$$

and that $E\left(r_{t}|| r_{t} \mid<x\right)$ is increasing in $x$. Therefore $E\left(\sum_{t=1}^{T} r_{t} I_{\left|r_{t}\right| \leq x}\right)$ is likewise increasing in $x$ and, by plotting

$$
\sum_{t=1}^{T} r_{t} I_{\left|r_{t}\right|<x}
$$

for some preselected and fixed values of $x$ and joining points by straight lines, one should, on average (i.e. by averaging over independent draws from the random 
variables (3)); obtain a monotonically increasing function. In practice, however, what one often observes looks like this:
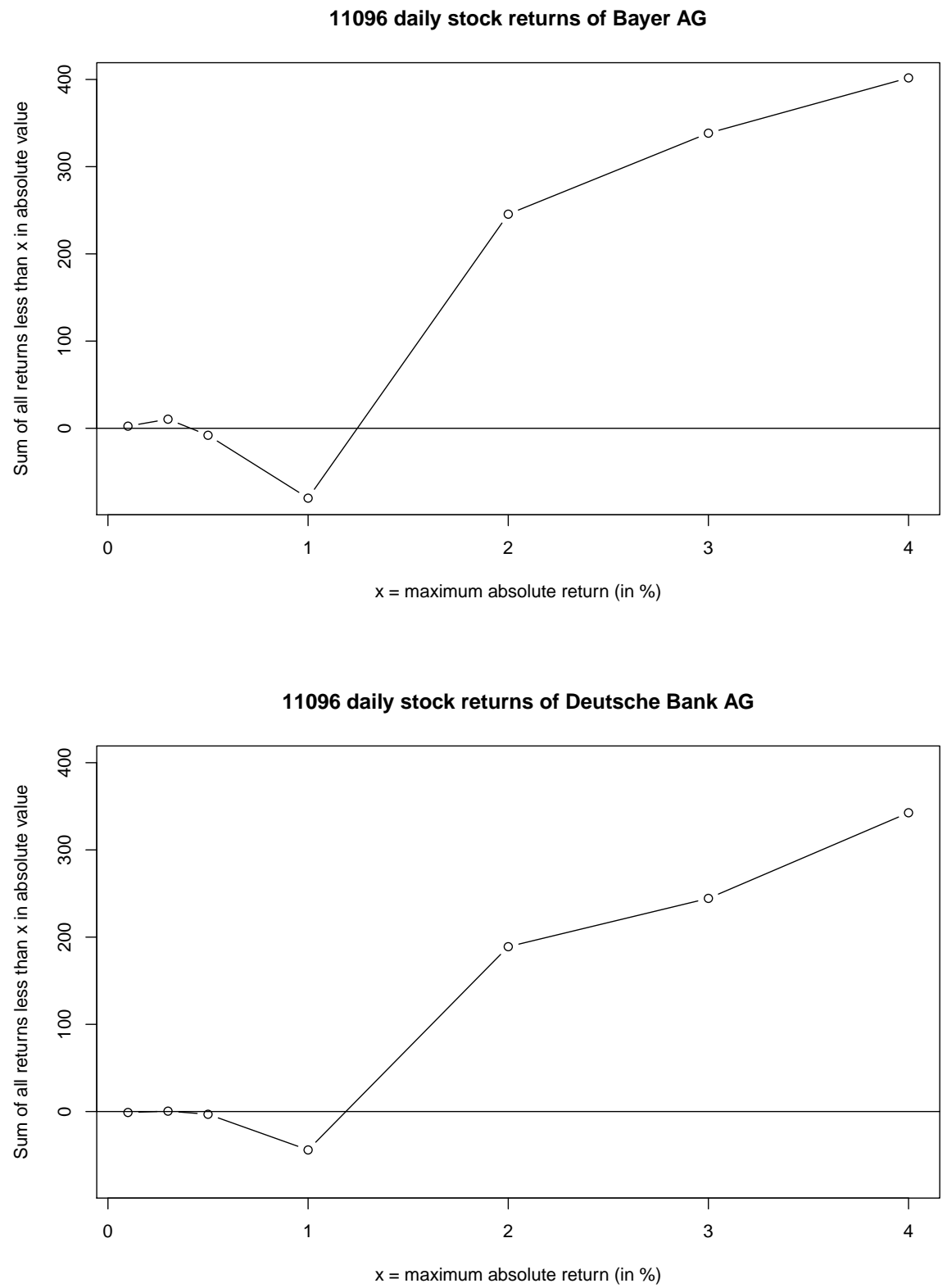

Figure 1: Aggregrated stock returns of Bayer and Deutsche Bank plotted against maximum absolute value.

Or more formally: The distribution of $r_{t}$ cannot be exactly symmetric around 
some nonnegative mean. And the spoon shaped-pattern from figure 1 indicates a particular form of asymmetry; it repeats itself for many other constituents of the German stock price index DAX, for half the constituents of the Dow Jones Industrial average and for many other individual stocks. In particular, the sum of all returns less than $1 \%$ in absolute value is very often negative. We call this a semi-stylized fact because it is not as universal as excess kurtosis but too frequent to be easily explainable by chance (given symmetrically distributed returns).

Our analysis below is mainly descriptive, with the aim of soliciting a more thorough discussion both from the viewpoint of economics and statistics. For an in-depth statistical discussion of various stylized facts of stock returns and how to model them see Davies and Krämer (2015).

\section{Additional empirical evidence}

Figure 2 plots 256, 356 daily returns, covering the years 1973-2015 of all companies which are currently covered by the German stock price index DAX, from 1973 to 2015.

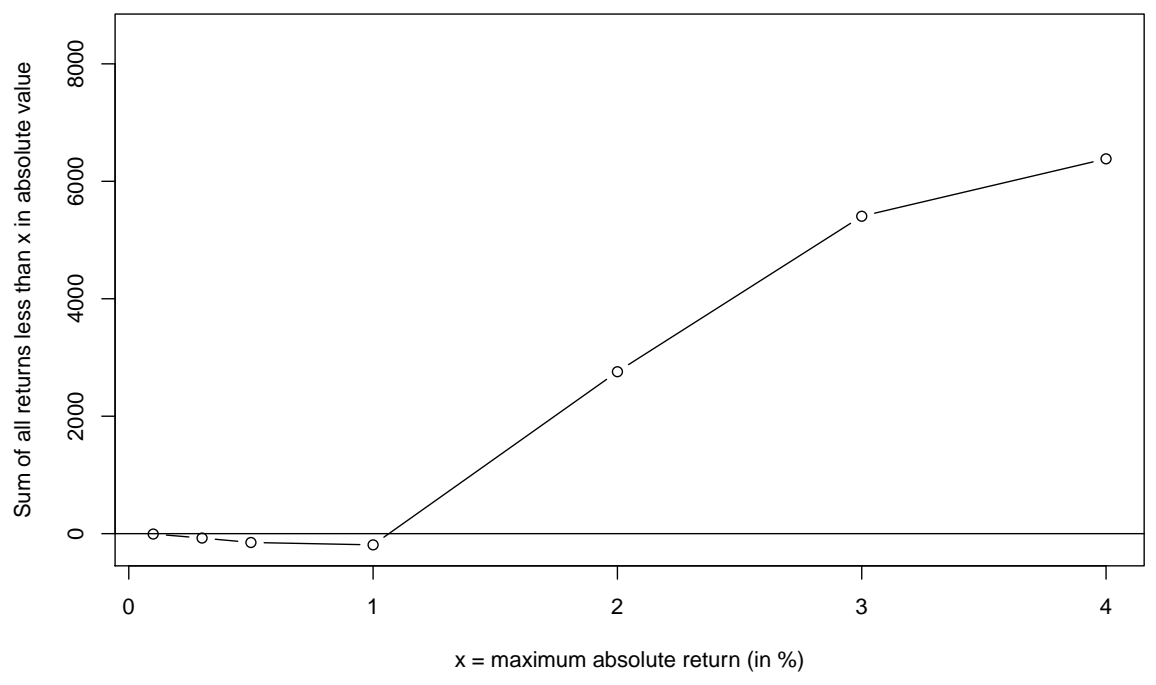

Figure 2: 256356 daily German stock returns. 
The pattern shown above for Bayer and Deutsche Bank persists, albeit less pronounced. Figure A1 in the appendix repeats this exercise for the remaining 28 DAX-constituents. It shows that for 21 of the remaining 28 companies, cumulated returns with absolute value less than $x$ are negative for $x$ in some range between 0.5 and 2 .

Table 1 reports a count of positive and negative returns - excluding zeros with absolute values less than some threshold for all DAX-companies. It shows that, overall, the percentage of negatives is slightly smaller than that of positives for most companies (23 out of 30 ), with both numbers clustering around $50 \%$, as one would expect from a return distribution which is symmetric around some small nonnegative mean (small in relation to the spread). However, for small thresholds, the percentage of negatives increases, with 21 companies each reporting more negatives for a threshold of $0.5 \%$ and $1 \%$.

We also checked the spoon effect for an independent data set composed of the constituents of the Dow Jones Industrial Average. The results are in the appendix and show that there exists a spoon effect for may shares, but less than for the constituents of the DAX. This might point to liquidity - which is larger for constituents of the Dow Jones than for constituents of the DAX - as a possible explanation; see below. As an example, figure 3 exhibits the spoon effect for Pfizer and American Express. 
Table 1: Percentage of negative returns among returns with absolute value less than some threshold

\begin{tabular}{|c|c|c|c|c|c|c|c|c|c|c|c|c|}
\hline \multirow[b]{3}{*}{ Company } & \multicolumn{12}{|c|}{ threshold } \\
\hline & \multicolumn{3}{|c|}{$0.5 \%$} & \multicolumn{3}{|c|}{$1 \%$} & \multicolumn{3}{|c|}{$2 \%$} & \multicolumn{3}{|c|}{$\infty$} \\
\hline & + & - & $\%$ & + & - & $\%$ & + & - & $\%$ & + & & $\%$ \\
\hline Adidas & 596 & 634 & 0.52 & 1137 & 1204 & 0.51 & 1809 & 1886 & 0.51 & 2436 & 2432 & 0.50 \\
\hline Allianz & 1600 & 1549 & 0.49 & 2843 & 2743 & 0.49 & 4204 & 3990 & 0.49 & 5193 & 4940 & 0.49 \\
\hline BASF & 1691 & 1733 & 0.51 & 3062 & 3102 & 0.50 & 4522 & 4325 & 0.49 & 5320 & 5098 & 0.49 \\
\hline Bayer & 1678 & 1641 & 0.49 & 2998 & 3058 & 0.50 & 4441 & 4278 & 0.49 & 5308 & 5091 & 0.49 \\
\hline Beiersdorf & 1564 & 1535 & 0.50 & 2848 & 2746 & 0.49 & 4015 & 3862 & 0.49 & 4793 & 4557 & 0.49 \\
\hline BMW & 1444 & 1497 & 0.51 & 2676 & 2702 & 0.50 & 4122 & 4042 & 0.50 & 5197 & 5065 & 0.49 \\
\hline Commerzbank & 1434 & 1423 & 0.50 & 2642 & 2719 & 0.51 & 3981 & 4024 & 0.50 & 5116 & 5185 & 0.50 \\
\hline Continental & 1244 & 1219 & 0.49 & 2333 & 2387 & 0.51 & 3739 & 3805 & 0.50 & 5154 & 5074 & 0.50 \\
\hline Daimler & 482 & 479 & 0.50 & 926 & 899 & 0.49 & 1551 & 1501 & 0.49 & 2112 & 2079 & 0.50 \\
\hline Deutsche Bank & 1676 & 1710 & 0.51 & 2888 & 2998 & 0.51 & 4295 & 4267 & 0.50 & 5231 & 5201 & 0.50 \\
\hline Deutsche Boerse & 485 & 481 & 0.50 & 892 & 878 & 0.50 & 1389 & 1366 & 0.50 & 1844 & 1764 & 0.49 \\
\hline Deutsche Post & 499 & 497 & 0.50 & 942 & 920 & 0.49 & 1480 & 1430 & 0.49 & 1860 & 1790 & 0.49 \\
\hline Deutsche Telekom & 626 & 657 & 0.51 & 1153 & 1207 & 0.51 & 1754 & 1764 & 0.50 & 2305 & 2333 & 0.50 \\
\hline E.ON & 1711 & 1759 & 0.51 & 3060 & 3046 & 0.50 & 4487 & 4302 & 0.49 & 5249 & 5084 & 0.49 \\
\hline Fresenius Medical Care & 661 & 680 & 0.51 & 1241 & 1255 & 0.50 & 1854 & 1878 & 0.50 & 2341 & 2321 & 0.50 \\
\hline Fresenius & 639 & 678 & 0.51 & 1297 & 1301 & 0.50 & 2050 & 1999 & 0.49 & 2754 & 2611 & 0.49 \\
\hline HeidelbergCement & 1206 & 1320 & 0.52 & 2274 & 2461 & 0.52 & 3474 & 3641 & 0.51 & 4645 & 4782 & 0.51 \\
\hline Henkel & 638 & 676 & 0.51 & 1190 & 1231 & 0.51 & 1846 & 1897 & 0.51 & 2340 & 2321 & 0.50 \\
\hline Infineon Technologies & 330 & 348 & 0.51 & 653 & 657 & 0.50 & 1114 & 1147 & 0.51 & 1887 & 1946 & 0.51 \\
\hline $\mathrm{K}+\mathrm{S}$ & 1186 & 1307 & 0.52 & 2376 & 2543 & 0.52 & 3741 & 3904 & 0.51 & 4973 & 4996 & 0.50 \\
\hline Lanxess & 266 & 270 & 0.50 & 490 & 546 & 0.53 & 856 & 907 & 0.51 & 1316 & 1322 & 0.50 \\
\hline Linde & 1683 & 1728 & 0.51 & 3021 & 3088 & 0.51 & 4333 & 4321 & 0.50 & 5139 & 5029 & 0.49 \\
\hline Deutsche Lufthansa & 1038 & 1070 & 0.51 & 2115 & 2206 & 0.51 & 3596 & 3672 & 0.51 & 4984 & 5002 & 0.50 \\
\hline Merck & 664 & 716 & 0.52 & 1187 & 1253 & 0.51 & 1885 & 1870 & 0.50 & 2460 & 2404 & 0.49 \\
\hline Munich Re & 1357 & 1316 & 0.49 & 2562 & 2455 & 0.49 & 3855 & 3653 & 0.49 & 4920 & 4641 & 0.49 \\
\hline RWE & 1791 & 1803 & 0.50 & 3100 & 3055 & 0.50 & 4369 & 4252 & 0.49 & 5153 & 5039 & 0.49 \\
\hline SAP & 830 & 856 & 0.51 & 1612 & 1550 & 0.49 & 2527 & 2334 & 0.48 & 3401 & 3132 & 0.48 \\
\hline Siemens & 1772 & 1780 & 0.50 & 3105 & 3027 & 0.49 & 4502 & 4232 & 0.48 & 5345 & 5065 & 0.49 \\
\hline ThyssenKrupp & 1301 & 1326 & 0.50 & 2437 & 2471 & 0.50 & 3953 & 3933 & 0.50 & 5187 & 5095 & 0.50 \\
\hline Volkswagen & 1267 & 1365 & 0.52 & 2449 & 2567 & 0.51 & 3958 & 4055 & 0.51 & 5204 & 5180 & 0.50 \\
\hline
\end{tabular}


11249 daily stock returns of American Express

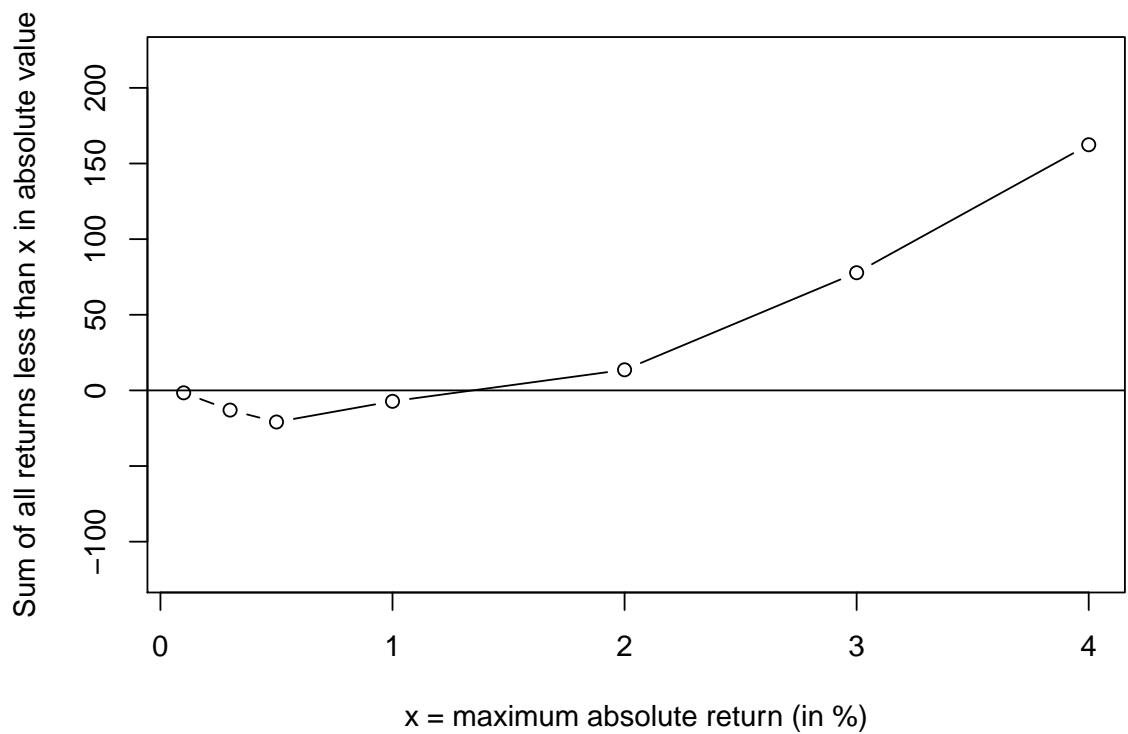

11249 daily stock returns of Pfizer

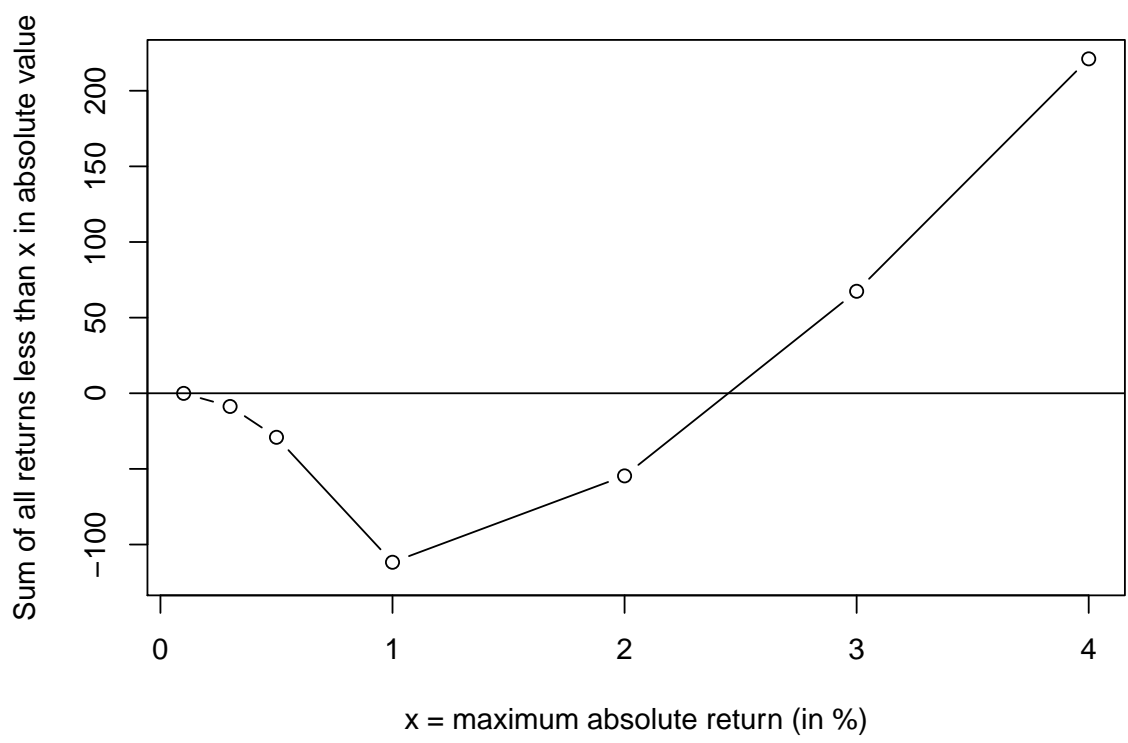

Figure 3: Spoon effect for Pfizer and American Express. 


\section{Possible explanations}

The major purpose of the present note is to point out the effect as such. We are not concerned with its consistency with more elaborate models for returns, as for instance discussed in Davies and Krämer (2015). Among possible economic explanations, one might think of transaction costs and small differences between "true" (=efficient) prices and the market price induced by them: to the extent that efficient prices are more often slightly above than slightly below the market price, and changes of efficient prices cluster around zero, small negative changes in the market price are more frequent than they otherwise would be. Likewise, other market microstructure specifics such as short selling restrictions might induce a prevalence of small negative changes, along the lines of Diamond and Verrechia (1987): As traders who perceive a reduction in the efficient price are not allowed to sell, it takes longer for negative information to affect the market price, which then adjusts downwards not at once but in consecutive smaller steps. This is in line with the observation from the microstructure literature that bad news and trading volume are often negatively correlated.

Another simple explanation that comes to mind is what in marketing is called a threshold effect (Bemmaor (1984)): If we keep to the basic assumption that stock prices are moved by news, then one might hypothesize that information pertaining to the value of a stock has to cross some importance-threshold to be recognized in the first place by either the media or the investor or both. And according to the old saying "only bad news is good news", this threshold might be lower for bad news on the margin of general importance. A cursory perusal of two leading German business papers, Frankfurter Allgemeine Zeitung and Handelsblatt, indeed provides empirical evidence that firm specific borderlinenews - defined as appearing in only one of the papers, but not in both - are predominantly negative. Therefore, the spoon effect should be weaker or disappear if returns are averaged across firms. Figure 4 shows that this is indeed the case for both Bayer and Deutsche Bank and Pfizer and American Express. Each individual return exhibits a marked spoon effect, but the respective averages do not. 


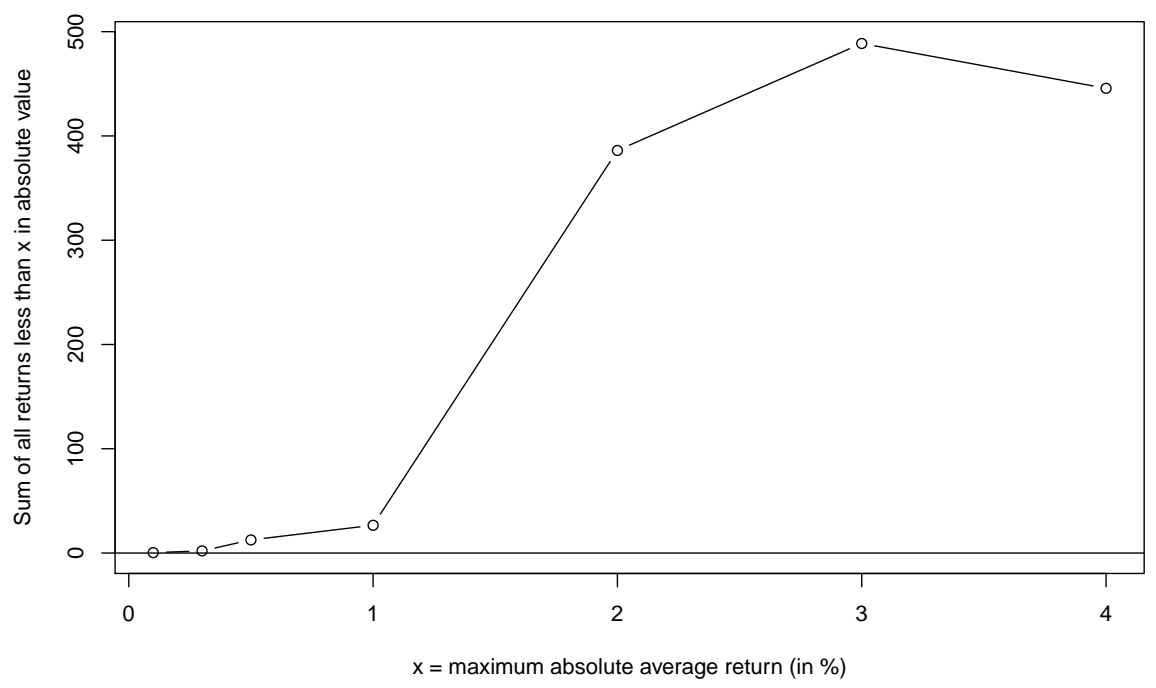

(a) Average of 11096 daily stock returns for Deutsche Bank and Bayer.

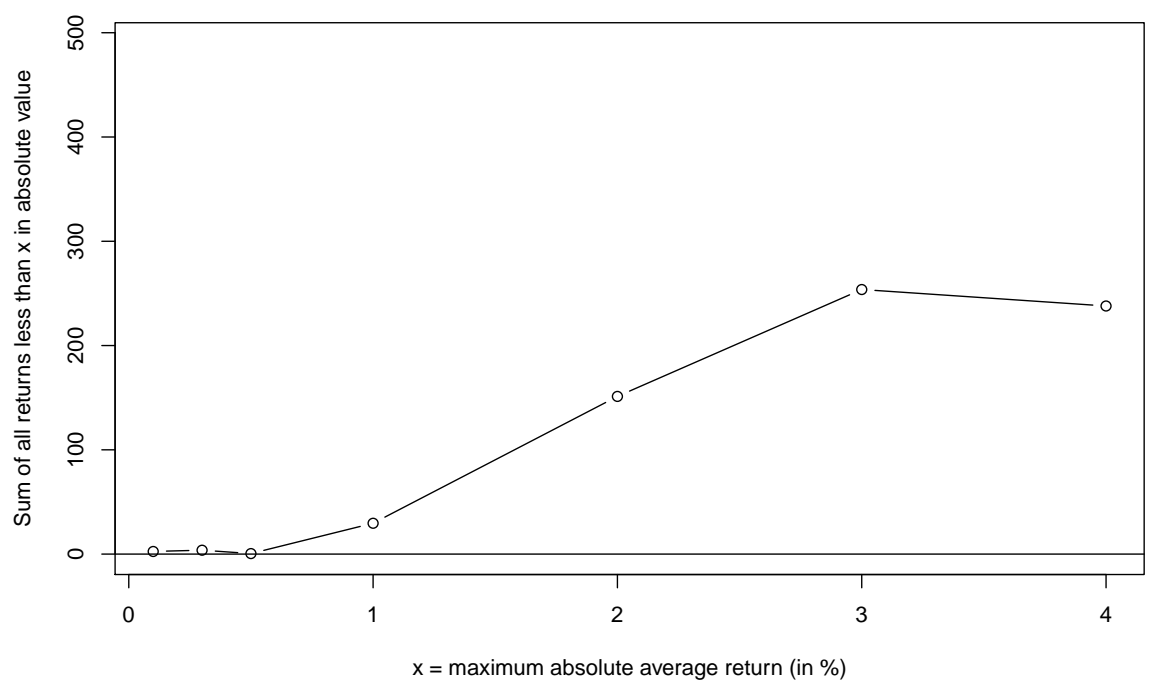

(b) Average of 11249 daily stock returns for American Express and Pfizer.

Figure 4: No spoon effect for average returns.

Similarly, the returns of the DAX and the Dow Jones do not show any spoon effect (see figure 5). 


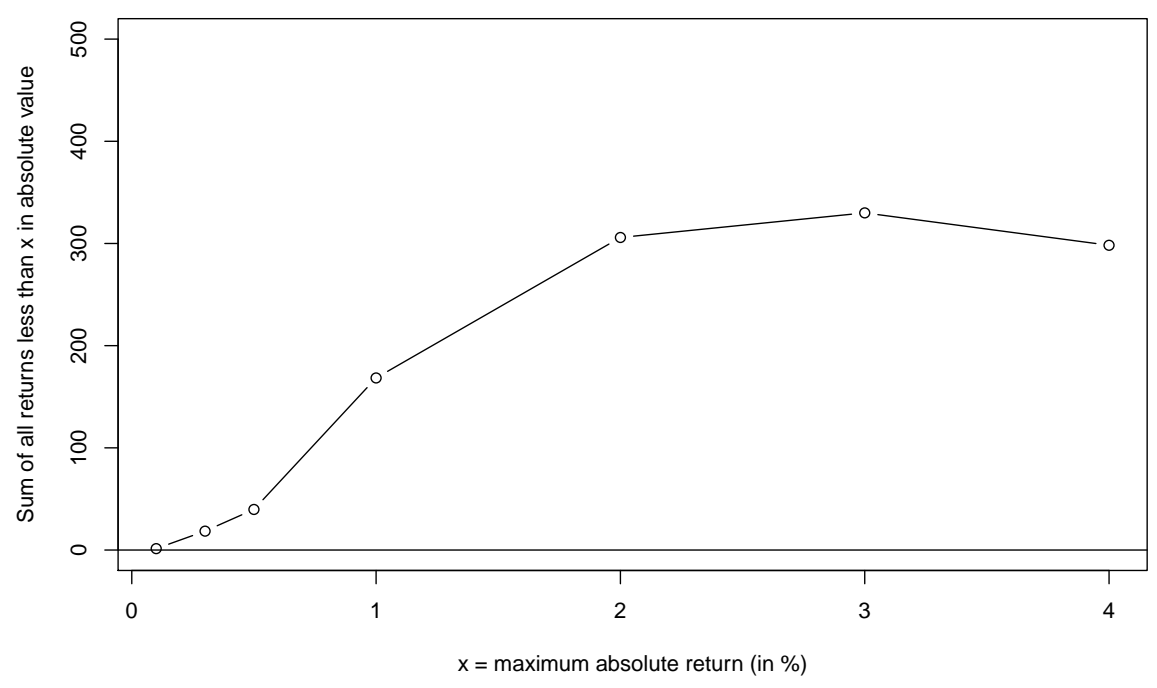

(a) 6350 daily DAX returns.

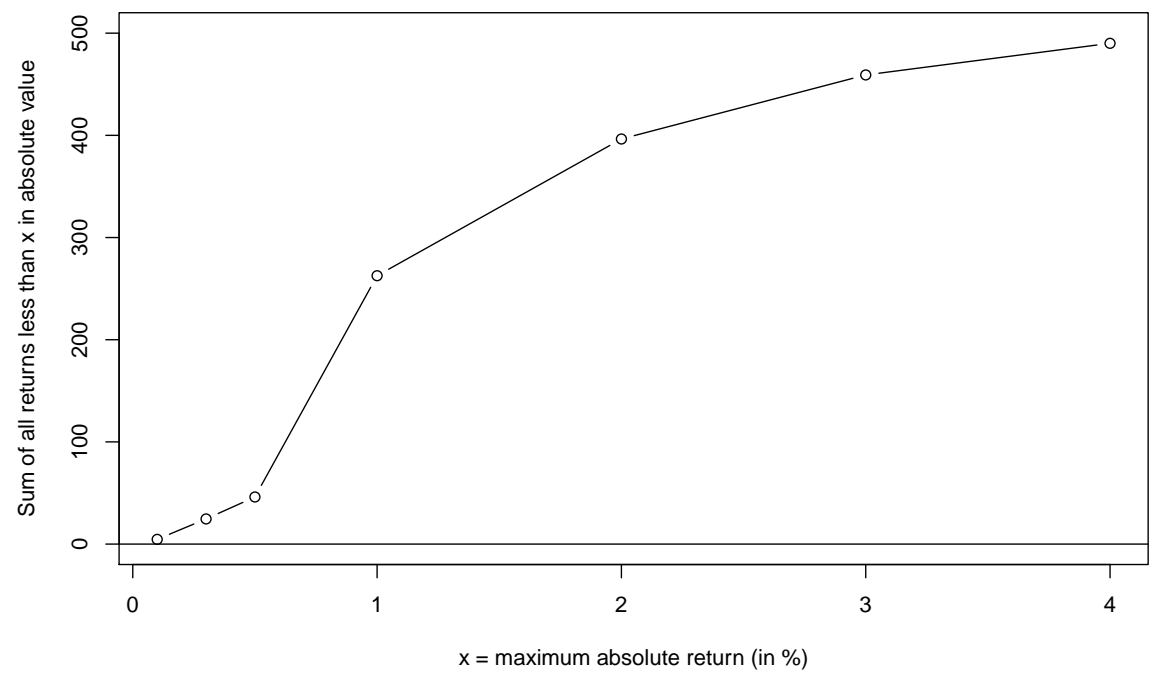

(b) 15133 daily Dow Jones returns.

Figure 5: No spoon effect for price indices.

Still another avenue which might be worth exploring is the observation by Kudryavtsev (2013) that returns are lower following days with relatively large 
low-to-close price differences. While this so far is only correlation, it might help to identify a common factor responsible for both.

Finally, it might be worth noting that the spoon effect presented here is not an artifact of using discrete time returns: If time-continuous returns are symmetric and normal with mean zero, is is easily seen that discrete-time returns must then exhibit some spoon effect due to the skewness of the lognormal distribution. But returns used in the examples above are already in continuous time. 


\section{References}

Bemmaor, A. C. (1984). Testing alternative econometric models on the existence of advertising threshold effect. Journal of Marketing Research, 21, 289-308.

Cont, R. (2001). Empirical properties of asset returns: stylized facts and statistical issues. Quantitative Finance, 1, 223-236.

DAvies, L. and Krämer, W. (2015). Stylized facts and simulating long range financial data. SFB 823 discussion paper, 48/15, Dortmund https://www.statistik.tu-dortmund.de/fileadmin/user_upload/ DP_4815_SFB823_Davies_Kraemer.pdf.

Diamond, D. W. and Verrechia, R. E. (1987): Constraints on short-selling and asset price adjustment to private information. Journal of Financial Economics, 18(2), 277-311.

Granger, C. W. J. and Ding, Z. (1995). Some properties of absolute returns: An alternative measure of risk, Annales d'Economie et de Statistique, 40, 6791.

Granger, C. W. J., Spear, S. A., and Ding, Z. (2000). Stylized facts on the temporal and distributional properties of absolute returns: An update, in Chan W. et al.: Statistics and Finance: An interface, 97-120.

KudRyavtsev, A. (2013). Stock price reversals following end-of-the-day price moves, Economics Letters, 118(1), 203-205.

Malmsten, H. and TerÄsvirta, T. (2010). Stylized facts of financial time series and three popular models of volatilty. European Journal of Pure and Applied Mathematics, 3(3), 443-477.

Rydén, T., TerÄsvirta, T. and Ȧsbrink, S. (1998). Stylized facts of daily return series and the hidden markov model. Journal of Applied Econometrics, 13, $217-244$.

TerÄsvirta, T. and ZhaO, Z. (2010). Stylized facts of return series, robust estimates and three popular models of volatility. Applied Financial Economics, 21(1), 67-94. 


\section{Appendix}

Figure A1: Daily stock returns for remaining DAX-constituents, where $\mathrm{x}$ denotes the returns (in \%) and $\mathrm{S}$ the sum of all returns less than $\mathrm{x}$ in absolute value (also in \%).
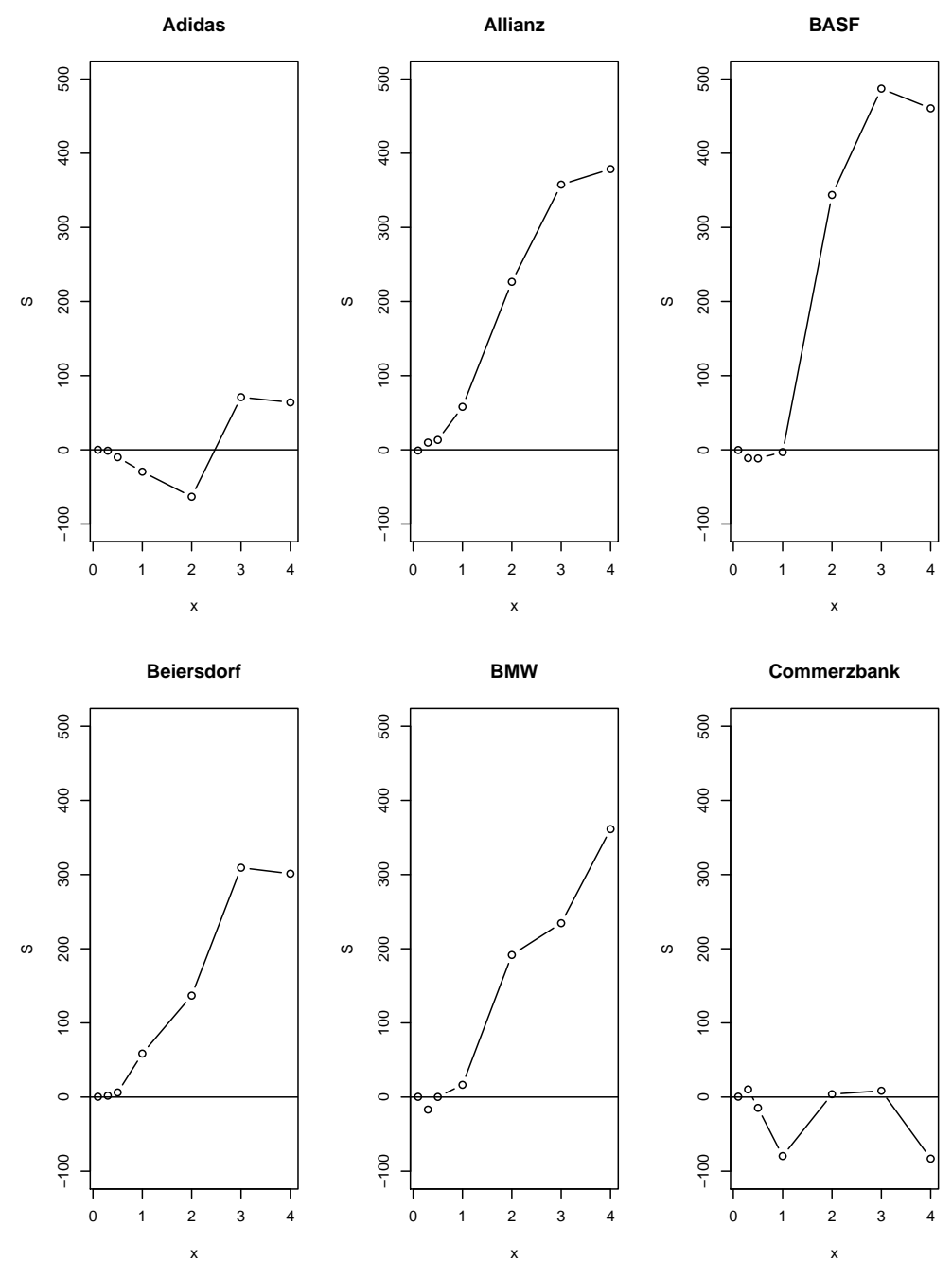

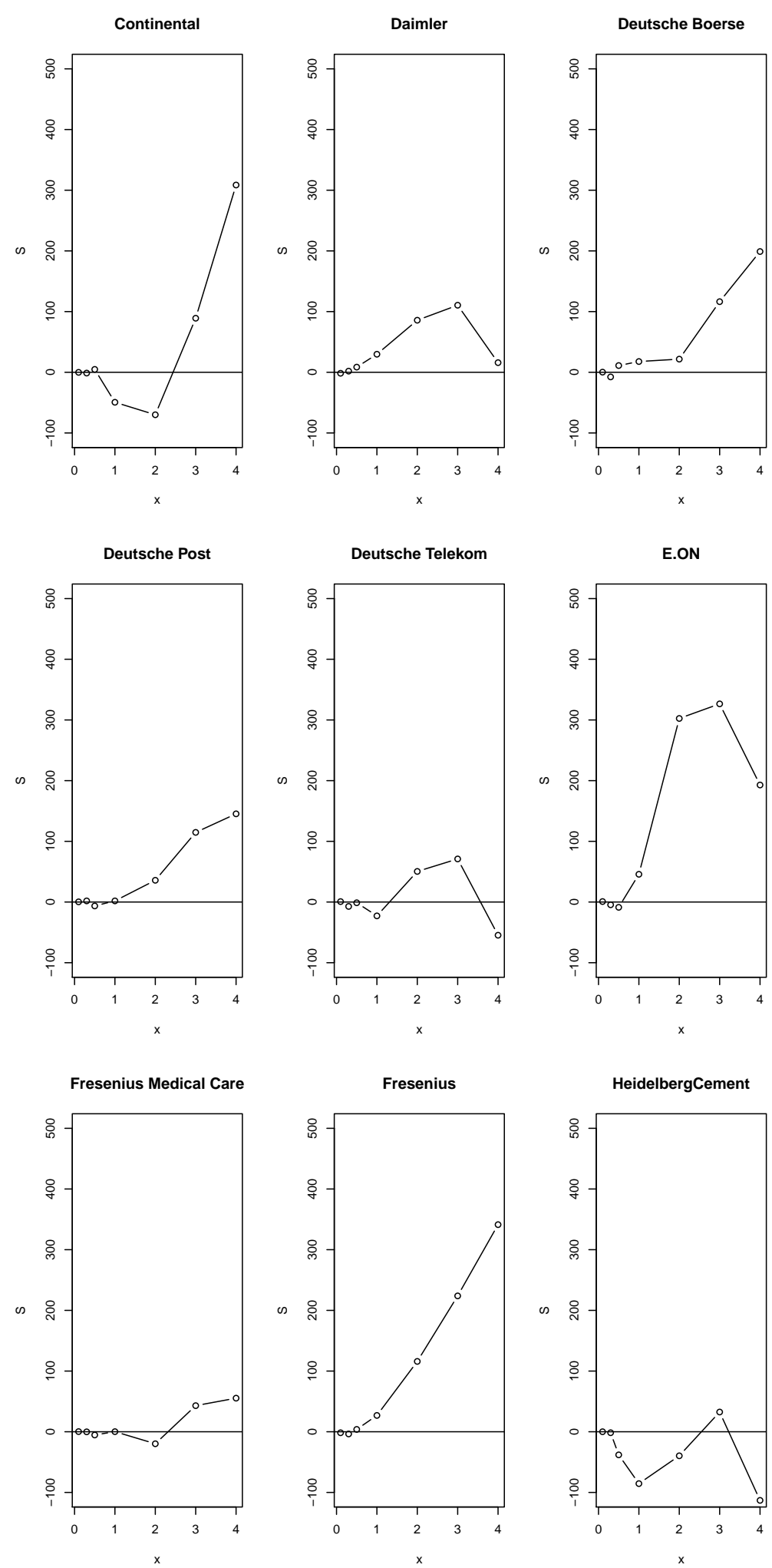

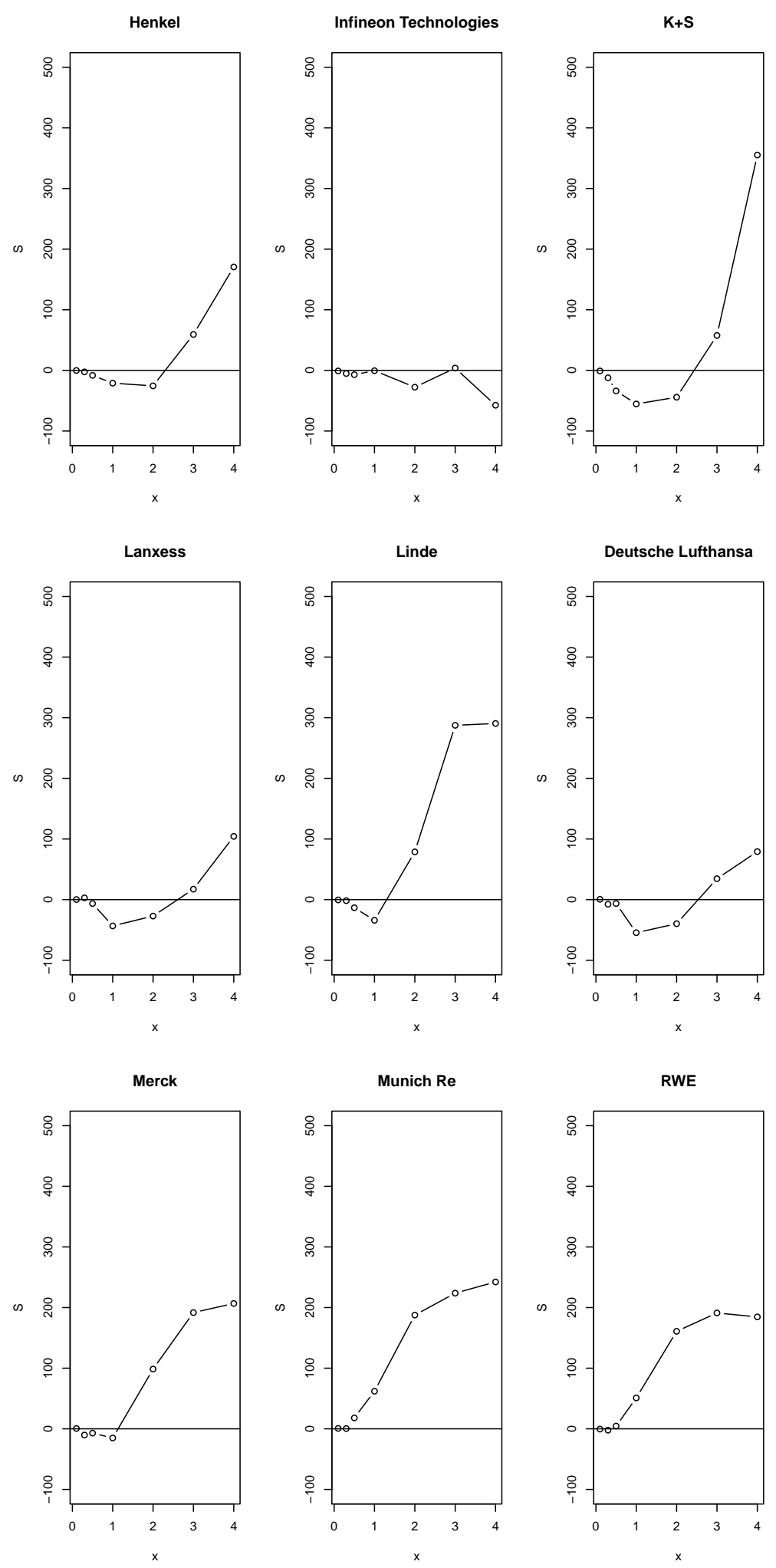

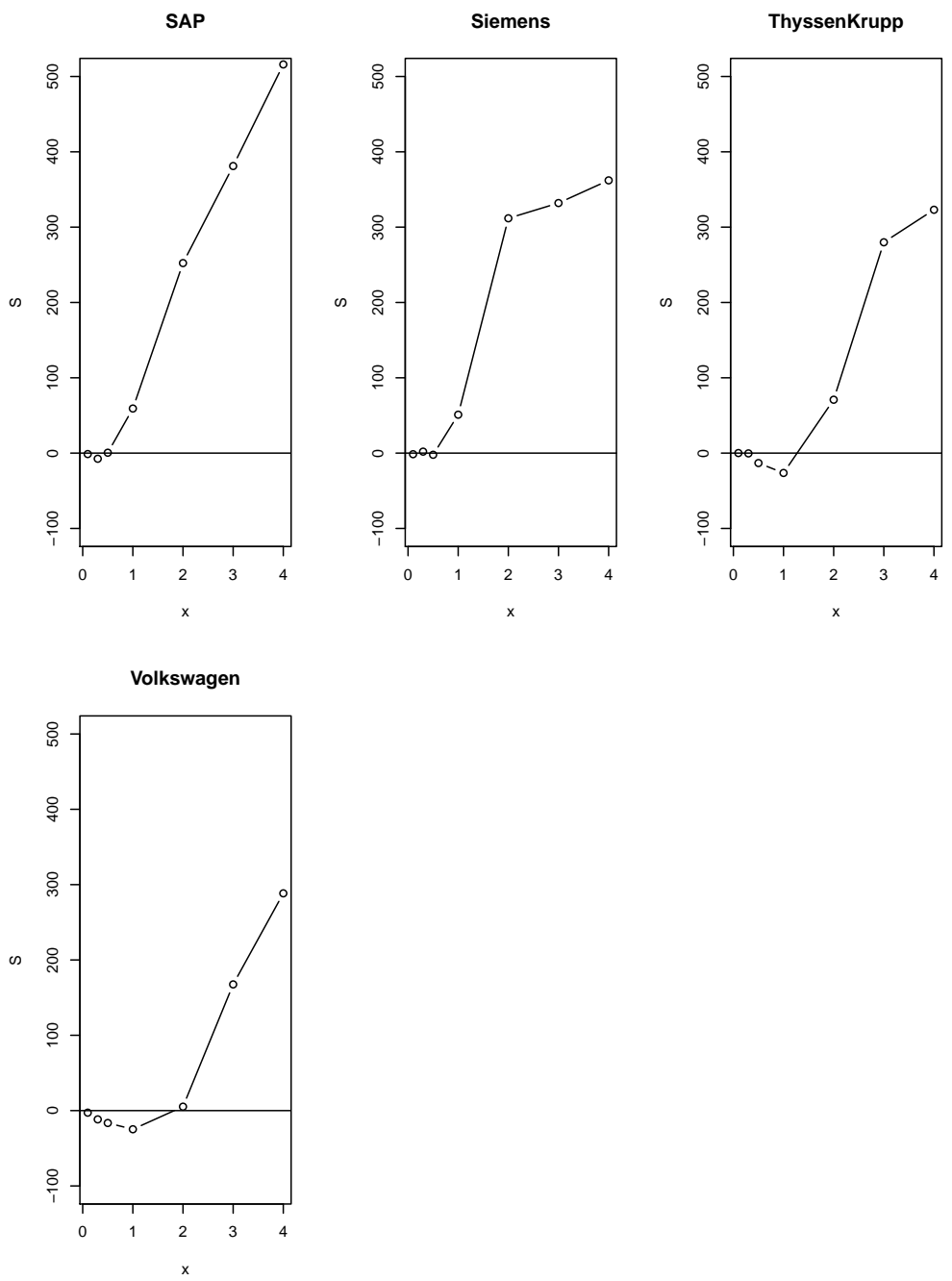

Figure A2: Daily stock returns for the Dow Jones-constituents, where $\mathrm{x}$ denotes the returns (in \%) and $\mathrm{S}$ the sum of all returns less than $\mathrm{x}$ in absolute value (also in \%).
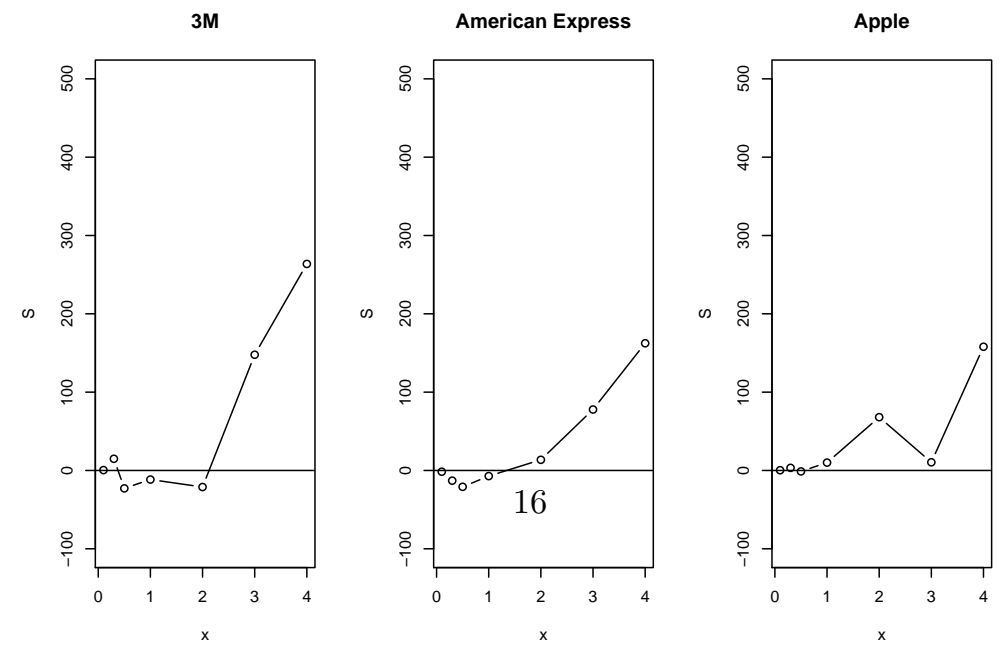

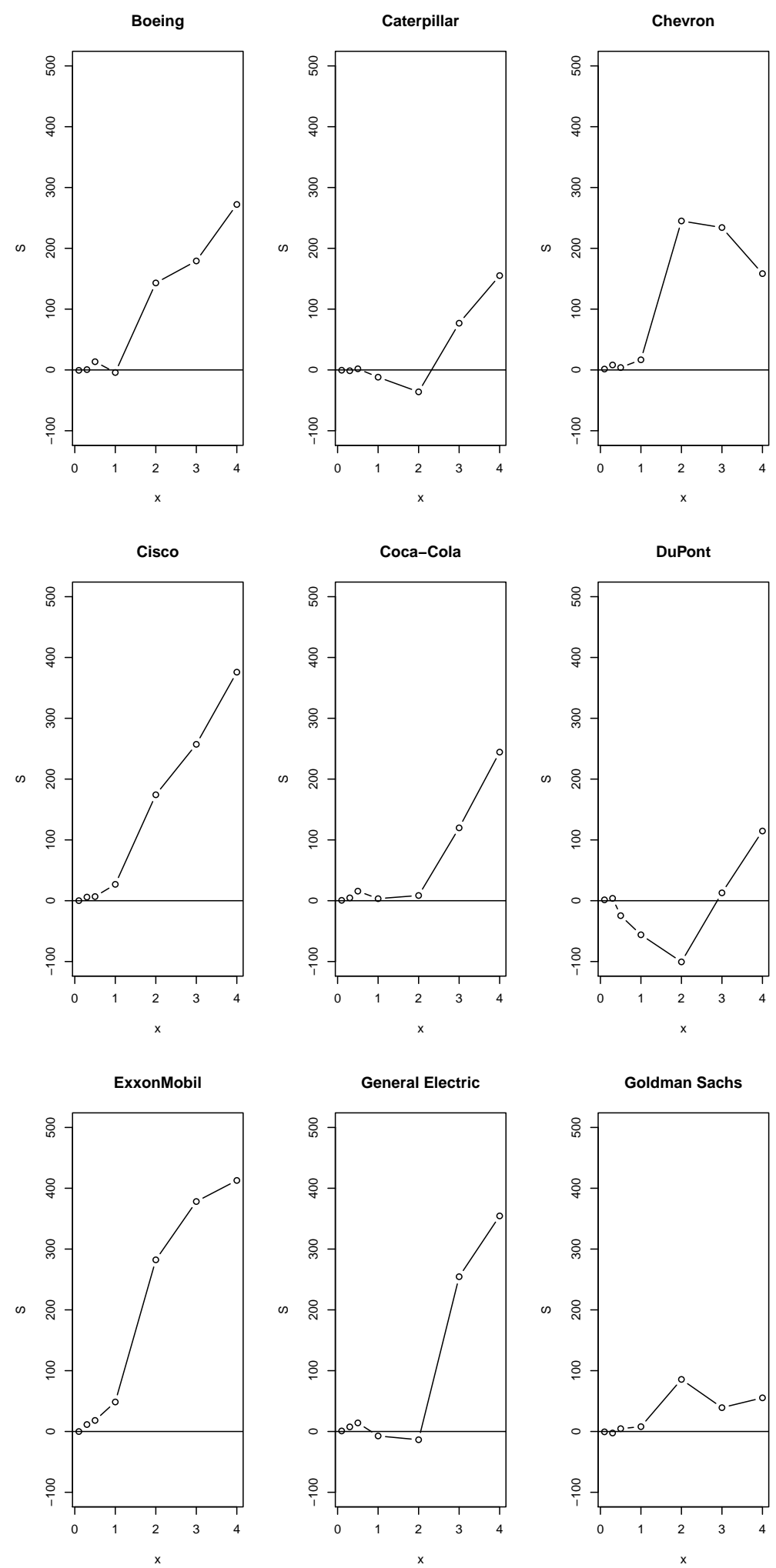

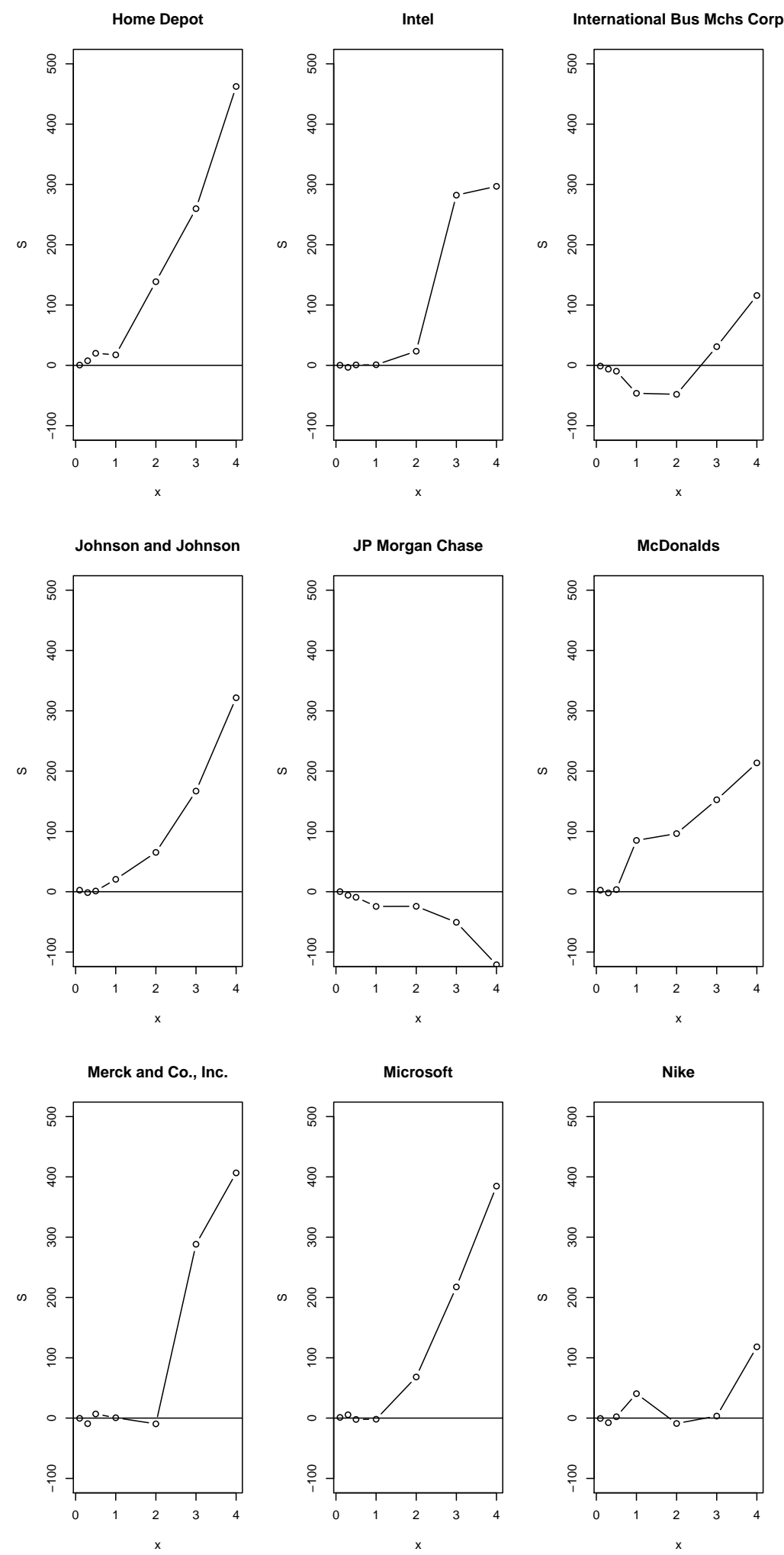

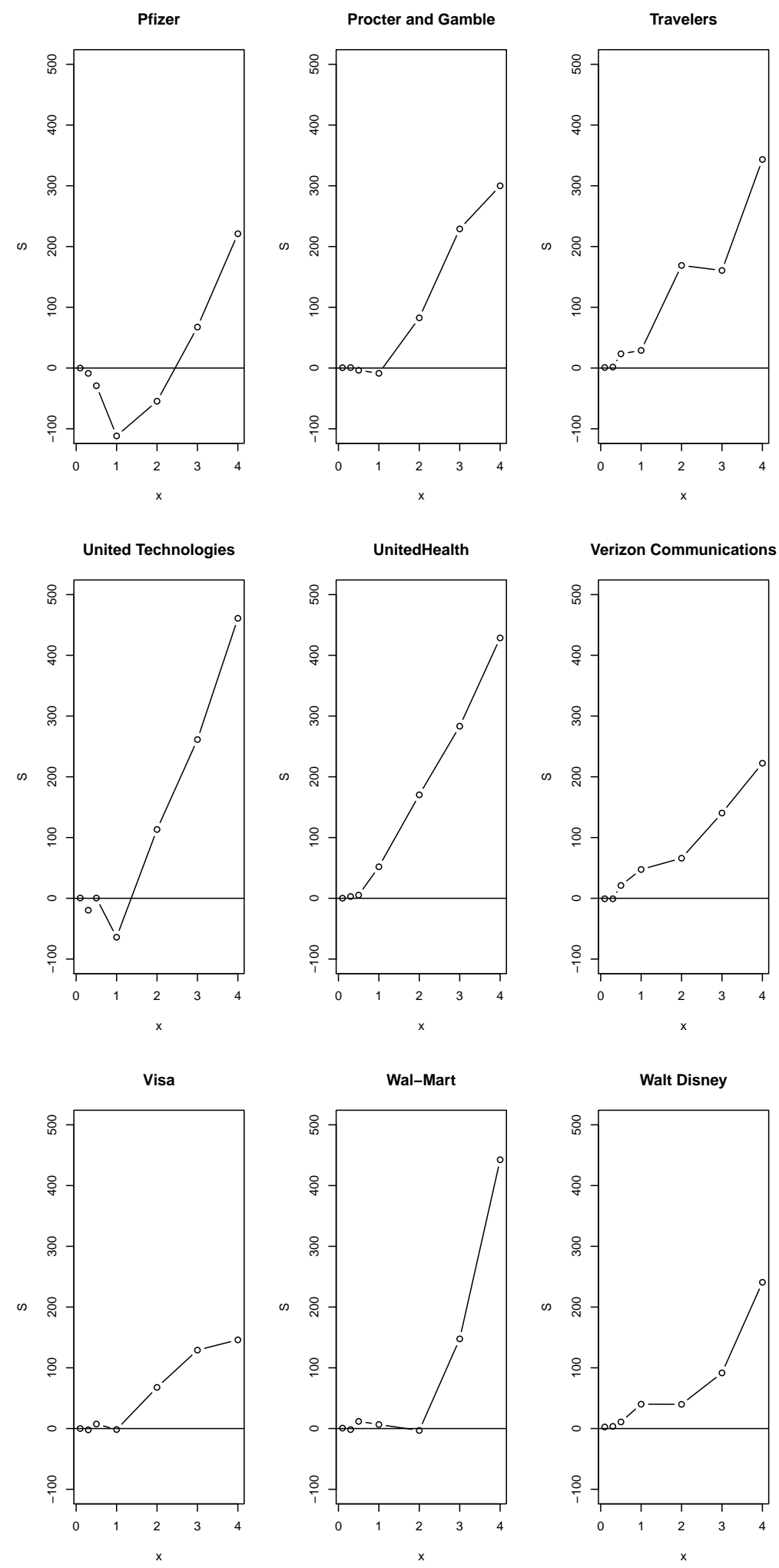